Research Article

\title{
Effects of Paving Technology, Pavement Materials, and Structures on the Fatigue Property of Double-Layer Pavements
}

\author{
Changqing Deng, Yingjun Jiang $(\mathbb{D}$, Zhanchuang Han, Hongwei Lin, and Jiangtao Fan
}

Key Laboratory for Special Area Highway Engineering of Ministry of Education, Chang'an University, Xi'an, Shaanxi 710064, China

Correspondence should be addressed to Yingjun Jiang; jyj@chd.edu.cn

Received 22 June 2019; Revised 25 July 2020; Accepted 3 August 2020; Published 5 October 2020

Academic Editor: Charles C. Sorrell

Copyright (c) 2020 Changqing Deng et al. This is an open access article distributed under the Creative Commons Attribution License, which permits unrestricted use, distribution, and reproduction in any medium, provided the original work is properly cited.

\begin{abstract}
Double-layer paving technology, which is a new technology for construction asphalt pavements, has received increasing research attention for several years. However, few studies have focused on the effect of asphalt pavement layer thickness and mixture-type combinations on the fatigue properties of a double-layer pavement. Therefore, the fatigue properties of the double-layer and traditionally paved asphalt pavements were studied in this work. The effects of two paving technologies, three mixture combinations, and two asphalt layer thickness combinations on the fatigue properties of asphalt pavements were studied through bending beam tests, and a fatigue equation of different asphalt pavements was established using the two-parameter Weibull distribution. Subsequently, the fatigue lives of different pavements were compared and analyzed under the same cyclic load. Results indicate that the flexural strength and fatigue life of the double-layer pavement increased by at least $10 \%$ and $54 \%$, respectively, compared with those of a traditionally paved pavement structure. The goodness of fit of the equation established using the Weibull distribution exceeded 0.90. For the traditional paving technology, compared with the pavement structure combination of 4-cm AC-13 surface layer/6-cm AC-20 bottom layer, the fatigue life of a 3-cm AC-13 surface layer/7-cm AC-20 bottom layer can be increased by at least $8 \%$, while the fatigue lives of other pavement structures are reduced significantly. The results also indicate that the fatigue life of the double-layer pavement structure with the 3-cm AC-13 surface layer/7-cm AC-20 bottom layer can be increased by at least $114 \%$ compared with that of the traditionally paved pavement structure $(4-\mathrm{cm}$ AC-13 surface layer/6-cm AC-20 bottom layer). Additionally, the fatigue lives of other pavement structures can be improved. To effectively improve the fatigue life of an asphalt pavement, a double-layer pavement structure with the 3-cm AC-13 surface layer/7$\mathrm{cm}$ AC-20 bottom layer combination is recommended.
\end{abstract}

\section{Introduction}

Pavement structures and material types significantly affect the fatigue life of an asphalt pavement [1-4]. The surface layer (4-cm AC-13), middle layer (6-cm AC-20), and lower layer (8-12-cm AC-25, ATB-25, or ATB-30) constitute the primary asphalt pavement structure of China's high-grade highways $[5,6]$. In addition, the 5-cm AC-13 surface layer/6$7-\mathrm{cm}$ AC-20 bottom layer combination is primarily used as the typical structure of the National Trunk Highway System of China [5, 6]. Most asphalt pavements were constructed using traditional paving technology, i.e., stratified spreading and layer-by-layer compaction because of the scarcity of construction machineries. In the field, a tacky coat oil is typically sprinkled between the asphalt structural layers to improve the adhesion force between the asphalt concrete layers $[7,8]$. However, although the tacky coat oil can improve the adhesion between two structural layers to some extent, the upper layer of a hot paving asphalt mixture cannot be embedded into the lower layer that has been cooled and compacted. Consequently, the extrusion effect of the aggregates between the two structural layers is poor, and their bonding action is weak. The poor "aggregate-binder" and "aggregate-aggregate" interfaces result in poor mechanical strength, moisture susceptibility, and poor highand low-temperature performance of asphalt concrete 
[9-11]. This seriously affects the reliability of the pavement design and the durability of the asphalt pavement [12], thereby increasing the cost of pavement construction and maintenance. In addition, many drawbacks such as rapid heat dissipation, long construction periods, and low work efficiency of construction machineries are difficult to avoid during traditional paving.

Double-layer paving technology for asphalt pavements, which is a new construction technology, simultaneously completes the paving and rolling of two structural layers $[13,14]$. The primary advantage of this paving technology is that the simultaneous paving and rolling of the two-layer asphalt structure, which can effectively avoid the "cold and hot combination" contact between two structural layers constructed by traditional paving, ensures that the two layers of asphalt concrete are simultaneously paved and compacted with the condition of the "hot and hot" contact. Thus, the asphalt in the upper- and lower-layer mixtures can be completely in contact with each other, and the aggregates in the upper- and lower-layer mixtures can be extruded together during the construction, thereby resulting in good adhesion and extrusion between the mixture layers $[15,16]$. Moreover, interlayer treatment is not applied during doublelayer paving, which not only saves the use of the tacky coat oil and shortens the construction period but also fundamentally solves the interlayer discontinuity problem of a traditionally paved pavement, thus ensuring a good bonding effect between the layers $[15,16]$. Other advantages, such as a reduction in the temperature loss of the asphalt mixture during construction and not being limited to the principle of 2.5-3.0 times between the pavement structure thickness and nominal maximum particle size of the aggregate in the asphalt mixture, are also significant [15-17]. At present, Sweden, the Netherlands, and Germany have mastered advanced double-layer paving technology. In Germany, the high-grade road surface with double-layer paving construction has reached $\sim 4$ million $\mathrm{m}^{2}$, and the road surface has been used well. The double-layer paving process has also been approved by the construction regulations of European countries such as Germany [18].

Recently, with the development and application of double-layer paving equipment, road construction researchers have conducted some studies on asphalt mixtures with double-layer paving technology. Großmann et al. considered that double-layer paving technology aids to improve the interlayer bonding effect of the asphalt layers [19]. Mueller found that double-layer paving technology fully utilized the thermal capacity stored in the lower-layer asphalt mixture, thereby allowing the upper layer asphalt mixture to easily reach a good compact state [20]. Morgan et al. explored the feasibility of applying double-layer paving technology to a double-layer large-gap asphalt pavement. The results indicated that it was feasible and more economical to apply this paving technology in constructing a large-gap asphalt pavement. Moreover, this technology not only improved the construction speed and reduced the temperature loss but also ensured that the asphalt mixture achieved better compactness [21]. Füleki considered that a double-layer asphalt pavement is advantageous for improving the aggregate interlocking effect between layers, thereby helping to resist the relative displacement between the layers caused by the shear stress generated by the traffic load [22]. Kuennan reported that the two-lift asphalt paving technology not only helps us to improve the durability of the asphalt pavement but also enhances its ability to resist traffic load and pavement distress [23]. Wang compared the interlaminar shear properties of field cores drilled from the traditional and double-layer paving pavements using the oblique shear test. The results indicated that the shear performance of the field cores drilled from the double-layer asphalt pavement increased significantly compared with that of the traditionally constructed pavement, and the test data were more stable. Moreover, a laboratory rutting test also indicated that the deformation resistance of the double-layer paved specimens was clearly better [24]. Gharabaghy et al. found that compared with the conventional asphalt pavements, the double-layer asphalt pavements showed better rutting resistance and shear strength [25]. Using field testing and laboratory analyses, Li demonstrated that double-layer paving can slow down the temperature reduction process and improve the compaction effect of asphalt pavements [26]. Liu et al. found that compared with the pavements constructed using conventional construction technology, the shear strength of the double-layer asphalt pavements was improved and the effective compaction time was extended [27]. Wang et al. established a finite element prediction model of mixture temperature loss based on heat conduction theory to study the effective rolling time and rolling temperature of the asphalt mixture with double-layer paving technology. Moreover, a test section was constructed to verify the model. The results indicated that the asphalt mixture with double-layer paving required a longer effective rolling time [28]. Yang et al. analyzed the interlayer stress distribution law of the double-layer pavement using a finite element and studied the fatigue performance of the double-layer pavement through laboratory tests. The results indicated that double-layer paving technology facilitated a reduction in the interlayer horizontal stress and improved the fatigue resistance of the asphalt pavement [29]. Jiang et al. studied the effect of paving technology, pavement materials, and structures on the rutting resistance of doublelayer pavements through laboratory tests. The results showed that the $3-\mathrm{cm}$ AC-16 surface layer/7-cm AC-20 bottom layer combination could improve the high-temperature rutting resistance of asphalt pavements [30].

The abovementioned studies have undoubtedly promoted the understanding of double-layer paving technology and the development of such technologies. However, related studies that were confined to the existing pavement structures and mixture-type combinations primarily investigated the effects of this paving technology on the bonding between the asphalt layers, temperature dispersion law during construction, shear performance, road performance, etc. Moreover, studies related to the effects of asphalt pavement layer thickness and mixture-type combinations on the fatigue properties of a double-layer pavement are scarce.

Fatigue life is the key performance parameter for asphalt pavements $[31,32]$. Asphalt pavement fatigue cracks due to 
insufficient fatigue life will gradually develop into cracks throughout the pavement structure. Furthermore, it will reduce the water damage resistance, road comfort, and safety of the asphalt pavement; shorten the service life of the road surface; increase the frequency of road surface maintenance and major and medium repair time; and increase the road life cycle cost [33-35]. At present, no standardized laboratory tests for fatigue cracking have been universally adopted for routine mix design or screening purposes for hot-mix asphalt crack resistance [36]. Globally, the commonly employed test methods are mainly the indirect tensile method, trapezoidal cantilever beam bending method, and bending beam method. The indirect tensile method is the most common in the early fatigue test of asphalt mixtures. However, owing to some shortcomings of its test mode, it is gradually being abandoned by asphalt mixture fatigue researchers. Trapezoidal cantilever beam bending and bending beam fatigue tests are the more popular fatigue test methods for small specimens. The former is mainly employed in Europe, while the latter has been the basis of numerous experimental studies and applications in the United States, South Africa, and Australia. The bending beam test piece is easy to manufacture, and the test operation is simple compared with that in the trapezoidal cantilever beam bending fatigue test. In addition, the bending beam fatigue test has excellent sensitivity in terms of testing influencing factors and reliability [37]. Therefore, in this study, the bending beam fatigue test is used to investigate the effects of structural asphalt layer thickness and mixture-type combinations on the fatigue properties of a double-layer paving pavement. The effects of two thickness combinations $(3-\mathrm{cm}$ surface layer/7- $\mathrm{cm}$ bottom layer and 4-cm surface layer/6$\mathrm{cm}$ bottom layer) and three mixture-type combinations (AC-13 surface layer/AC-20 bottom layer, AC-16 surface layer/AC-20 bottom layer, and AC-16 surface layer/AC-25 bottom layer) on the fatigue properties of the double-layer paving pavement were studied through laboratory tests. Subsequently, based on the optimal fatigue performance with double-layer paving technology, the mixture-type combination and pavement layer thickness are recommended.

\section{Materials and Methods}

\subsection{Materials}

2.1.1. Asphalt. In this study, Singapore Esso A-70 road petroleum asphalt, which was obtained from Shangluo City, Shaanxi Province, China, was used in the asphalt mixture. Moreover, the styrene-butadiene-styrene- (SBS-) (I-C) modified asphalt, which was collected from Karamay City, Xinjiang Uygur autonomous region, China, was used as the gluing material between two asphalt layers. The technical properties of the asphalt used in this study are listed in Table 1.

2.1.2. Aggregate. The coarse aggregate of the surface layer asphalt mixture used in this study was amphibolite obtained from Shangluo City, Shaanxi Province, China, while the coarse aggregate of the bottom layer asphalt mixture was limestone from Luonan City, Shaanxi Province, China. The fine aggregate of the surface and bottom layers' asphalt mixture was limestone from Luonan City, Shaanxi Province, China. The mineral powder used in this study was limestone ore powder from Luonan County, Shaanxi Province, China. All aggregates used in this study satisfied the technical specifications for the construction of highway asphalt pavements (JTG F40-2004) [17], and their technical indicators were omitted.

\subsection{Research Programs}

2.2.1. Test Plan. To study the effects of different mixture types on the fatigue properties of asphalt pavements, four types of asphalt mixtures were selected: AC-13, AC-16, AC20 , and $\mathrm{AC}-25$. The AC-13 or AC-16 asphalt mixture was used in the surface layer, whereas the AC- 20 or AC-25 asphalt mixture was used in the bottom layer. Table 2 gives the gradations of the asphalt mixtures used in this study. Moreover, Table 3 gives the design data of the asphalt mixtures, in which VV, VFA, VMA, MS, and FL are defined as the air void volume, volume of the voids filled with asphalt, voids in mineral aggregate, Marshall stability, and flow value of the asphalt mixture, respectively. It is noteworthy that all types of asphalt mixtures used in this study were designed by the standard Marshall procedure.

To study the effects of different pavement structure combinations on the fatigue properties of asphalt pavements, the total thickness of the asphalt pavement was set to $100 \mathrm{~mm}$, and two types of pavement structure combinations with different thicknesses of the surface and bottom layers were selected: $3-\mathrm{cm}$ surface layer/7- $\mathrm{cm}$ bottom layer and 4$\mathrm{cm}$ surface layer/6- $\mathrm{cm}$ bottom layer.

To study the effects of different paving technologies on the fatigue properties of asphalt pavements, two paving technologies were compared: the traditional and doublelayer paving technology.

2.2.2. Specimen Preparation Methods. The process of preparing mixture specimens by traditional paving technology for fatigue tests in the laboratory was divided into four primary stages:

(1) Mold the bottom layer cut board: a cut board of size $300 \mathrm{~mm} \times 300 \mathrm{~mm} \times 60 / 70 \mathrm{~mm}$

(length $\times$ width $\times$ height) was produced by a rolling compaction machine with its own optimal asphalt content. The rolling compaction machine stopped when the density of the cut board specimens and that of the standard cylindrical specimens were similar. Subsequently, the cut board specimens were kept at room temperature for at least $24 \mathrm{~h}$ (Figure 1(a)).

(2) Spray the sticky layer oil: the prepared bottom layer cut board was placed into a $300 \mathrm{~mm} \times 300 \mathrm{~mm} \times 100 \mathrm{~mm}$

(length $\times$ width $\times$ height) cut board mold. Subsequently, the SBS-modified asphalt of $0.45 \mathrm{~kg} / \mathrm{m}^{2}$ was 
TABLE 1: Technical properties of the asphalt used in this study.

\begin{tabular}{|c|c|c|c|c|c|c|c|}
\hline $\begin{array}{l}\text { Technical } \\
\text { index }\end{array}$ & $\begin{array}{c}\text { Penetration } \\
\left(25^{\circ} \mathrm{C}, 0.1 \mathrm{~mm}\right)\end{array}$ & Ductility $\left(10^{\circ} \mathrm{C}, \mathrm{cm}\right)$ & Soft point $\left({ }^{\circ} \mathrm{C}\right)$ & Relative density $\left(15^{\circ} \mathrm{C}\right)$ & Dissolvability (\%) & $\begin{array}{c}\text { Dynamic } \\
\text { viscosity } \\
\left(60^{\circ} \mathrm{C}, \mathrm{Pa} \cdot \mathrm{s}\right)\end{array}$ & $\begin{array}{c}\text { Engle } \\
\text { viscosity }\end{array}$ \\
\hline $\begin{array}{l}\text { A-70 } \\
\text { petroleum } \\
\text { asphalt }\end{array}$ & 73 & 37.1 & 47 & 1.019 & 99.7 & 236.5 & - \\
\hline $\begin{array}{l}\text { SBS- } \\
\text { modified } \\
\text { asphalt }\end{array}$ & 65 & 69.5 & 85 & 1.035 & 99.6 & - & 13.0 \\
\hline
\end{tabular}

TABLE 2: Aggregate gradations of the different asphalt mixtures used in this study.

\begin{tabular}{lccccccccccccc}
\hline \multirow{2}{*}{ Mixture types } & \multicolumn{10}{c}{ Percentage passing for sieve size $(\mathrm{mm})$} \\
& 31.5 & 26.5 & 19 & 16 & 13.2 & 9.5 & 4.75 & 2.36 & 1.18 & 0.6 & 0.3 & 0.15 & 0.075 \\
\hline AC-13 & - & - & - & 100 & 92.4 & 79.1 & 53.5 & 37.6 & 25.3 & 17.6 & 10.2 & 7.4 & 6.1 \\
AC-16 & - & - & 100 & 98.8 & 88.4 & 70.6 & 44.3 & 32.5 & 22.1 & 15.6 & 9.3 & 6.8 & 5.7 \\
AC-20 & - & 100 & 92.7 & 82.0 & 73.2 & 61.1 & 41.1 & 31.9 & 21.5 & 15.0 & 8.6 & 6.0 & 5.0 \\
AC-25 & 100 & 99.3 & 80.5 & 70.6 & 63.0 & 52.8 & 40.1 & 32.7 & 22.0 & 15.3 & 8.6 & 6.0 & 5.0 \\
\hline
\end{tabular}

TABLE 3: Design data of the asphalt mixtures used in this study.

\begin{tabular}{|c|c|c|c|c|c|c|c|}
\hline Mixture types & Optimal asphalt content (\%) & Density $\left(\mathrm{g} / \mathrm{cm}^{3}\right)$ & VV (\%) & VFA (\%) & VMA (\%) & MS (kN) & $\mathrm{FL}(\mathrm{mm})$ \\
\hline AC-13 & 4.7 & 2.510 & 3.1 & 74.4 & 14.1 & 12.4 & 3.7 \\
\hline AC- 16 & 4.5 & 2.492 & 3.5 & 73.1 & 14.3 & 13.2 & 3.2 \\
\hline AC-20 & 4.2 & 2.481 & 4.2 & 71.5 & 14.7 & 14.5 & 2.6 \\
\hline AC-25 & 3.8 & 2.462 & 5.4 & 70.9 & 15.4 & 13.7 & 3.0 \\
\hline
\end{tabular}

sprayed evenly on the cut board surface, with curing for at least $2 \mathrm{~h}$ (Figure $1(\mathrm{~b})$ ).

(3) Mold the surface layer cut board: a certain weight of the surface layer asphalt mixture was placed into the cut board mold and compacted by the rolling compaction machine until the height of the board was $100 \mathrm{~mm}$ (Figure 1(c)).

(4) Produce the beam specimen: the prepared cut board $(300 \mathrm{~mm} \times 300 \mathrm{~mm} \times 100 \mathrm{~mm})$ was cut into beam specimens of size $250 \mathrm{~mm} \times 100 \mathrm{~mm} \times 100 \mathrm{~mm}$ (length $\times$ width $\times$ height (Figure $1(\mathrm{~d})$ ).

The preparation process of the mixture specimens produced by the double-layer paving technology for the fatigue test in the laboratory was divided into three primary stages:

(1) Spread the bottom layer mixtures: a certain weight of the bottom layer asphalt mixture was placed into the cut board mold $(300 \mathrm{~mm} \times 300 \mathrm{~mm} \times 100 \mathrm{~mm})$ and subsequently placed into a $165^{\circ} \mathrm{C}$ oven after it was originally pressed using a hammer (Figure 2(a))

(2) Spread the surface layer mixtures and compaction: a certain weight of the surface layer asphalt mixture was placed into the cut board mold and compacted by the rolling compaction machine until the height was $100 \mathrm{~mm}$ (Figures 2(b) and 2(c))
(3) Produce the beam specimen: the prepared cut board $(300 \mathrm{~mm} \times 300 \mathrm{~mm} \times 100 \mathrm{~mm})$ was cut into beam specimens of size $250 \mathrm{~mm} \times 100 \mathrm{~mm} \times 100 \mathrm{~mm}$ (length $\times$ width $\times$ height), as shown in Figure $2(\mathrm{~d})$

2.2.3. Fatigue Test Method. The fatigue tests used to evaluate the fatigue property of asphalt mixtures in the laboratory primarily included the bending beam fatigue, indirect tension, and semicircular bending fatigue test [38, 39]. Compared with the indirect tension and semicircular bending fatigue test, the specimen preparation process of the bending beam fatigue test is more complicated and the experiment data dispersion is more significant. Moreover, the bending test could simulate the stress conditions of the actual pavement structures better and the experiment results could be directly used for asphalt pavement structure design. However, as the total thickness of the asphalt pavement structure was $100 \mathrm{~mm}$, it was difficult to perform the fatigue test using the indirect tension or semicircular bending fatigue test. Furthermore, the overlay test can be used to evaluate cracking resistance of asphalt overlays, but the overlay test device is scarce in China [33-36]. Therefore, the bending beam fatigue test was adopted to study the fatigue property of asphalt pavements. Figure 3 shows the fatigue test model used in this study.

Generally, two primary control modes exist for fatigue testing: the controlled-strain and controlled-stress. For the 


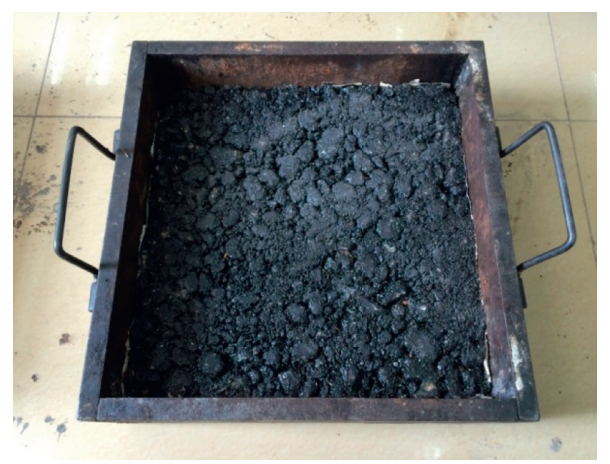

(a)

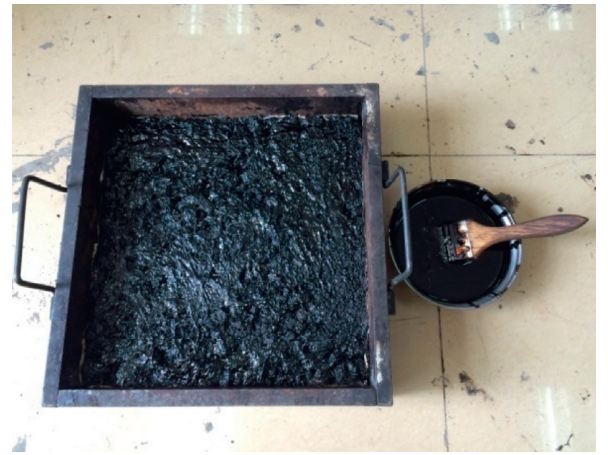

(b)
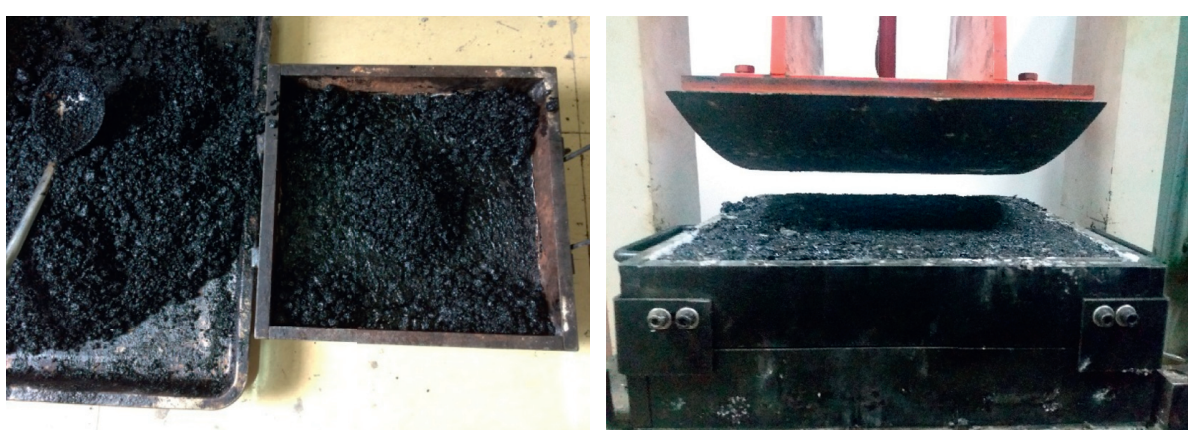

(c)
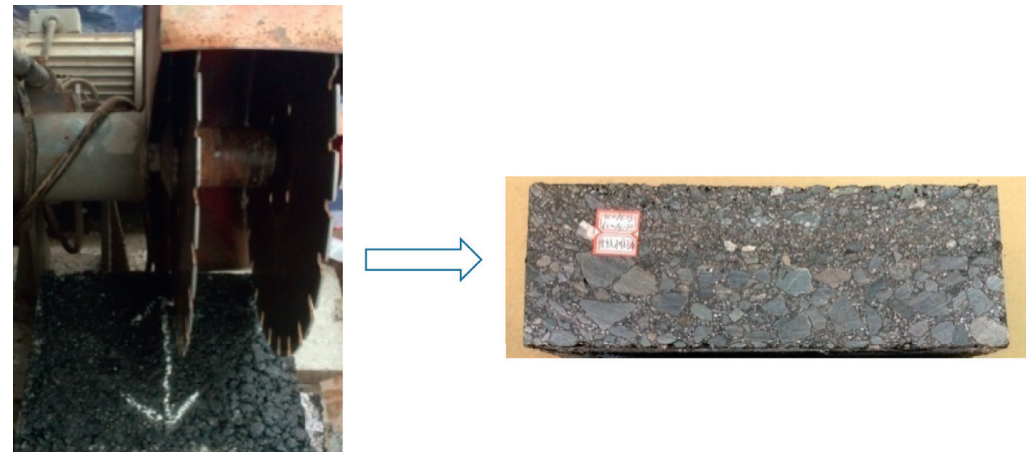

(d)

Figure 1: Traditional paved beam test specimen preparation process. (a) Mold the bottom layer cut board. (b) Spray the sticky layer oil. (c) Mold the surface layer cut board. (d) Produce the beam specimen.

controlled-strain fatigue test, the fatigue life of materials is defined as the number of load cycles corresponding to a $50 \%$ reduction in stiffness; meanwhile, for the controlled-stress test, the fatigue life of materials is defined as the number of load cycles corresponding to a fracture of specimens $[40,41]$. Because of beam inhomogeneity, the modulus of the beam could not be computed from the fatigue tests. Therefore, the controlled-stress test was used in this study, and the fatigue 

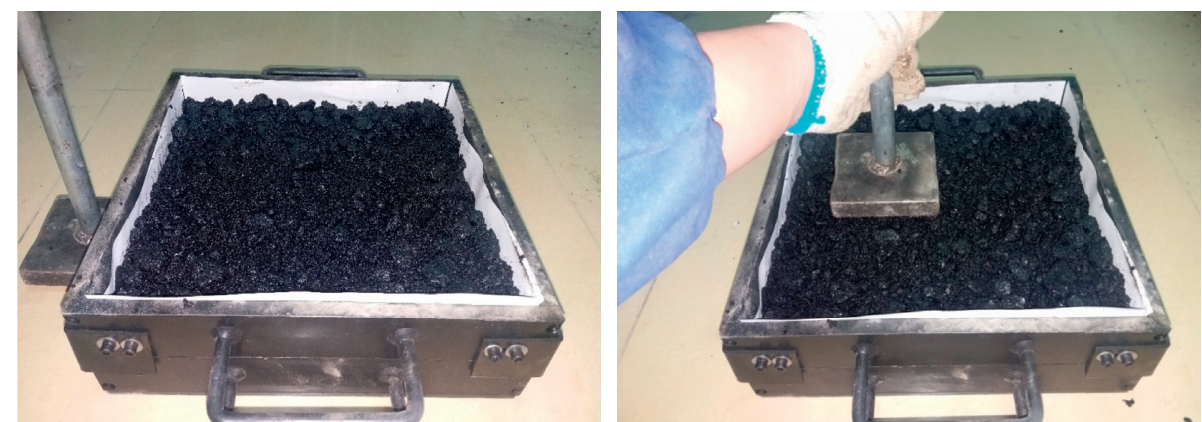

(a)
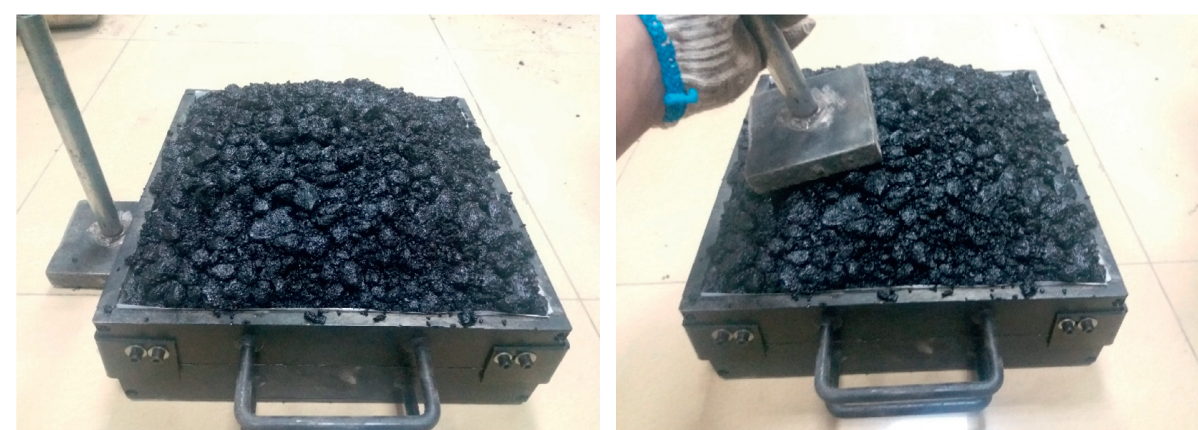

(b)

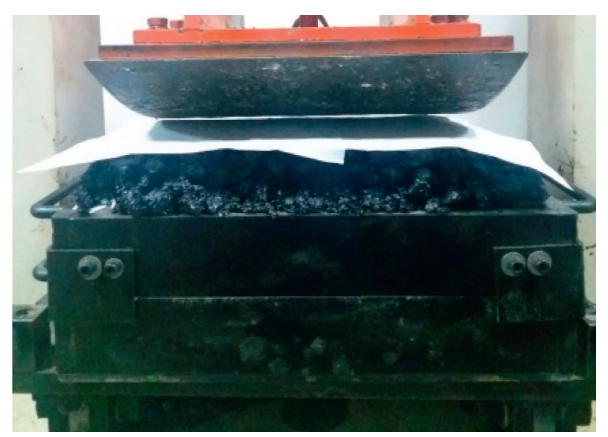

(c)

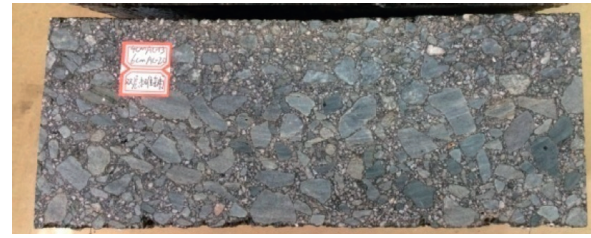

(d)

FIGURE 2: Double-layer paved beam test specimen preparation process. (a) Spreading the bottom layer mixtures and original compaction. (b) Spread the surface layer mixtures. (c) Compaction by rolling compaction machine. (d) Double-layer paved beam test specimen.

life of the beam was obtained according to the number of load cycles corresponding to the fracture of the specimens.

The bending beam fatigue test was divided into two primary stages:

(1) Bending beam test

The flexural strength of the beam specimen $(250 \mathrm{~mm} \times 100 \mathrm{~mm} \times 100 \mathrm{~mm})$ produced by the double-layer and traditional paving technologies was measured using a material test system (MTS). The test temperature was $15^{\circ} \mathrm{C}$, and the loading rate was $50 \mathrm{~mm} / \mathrm{min}$.

(2) Bending fatigue test

The fatigue test was conducted on the MTS at $15^{\circ} \mathrm{C}$. Sine wave loading was used. The loading waveform 


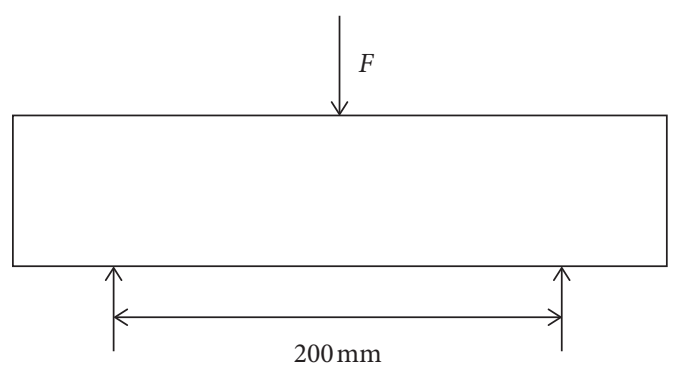

Figure 3: Fatigue test model.

diagram used in this study is shown in Figure 4. To maintain the contact between the indenter of the MTS and the specimens during the fatigue test, only vertical pressure (and no tension) was applied by the indenter. The loading frequency of the sine wave was $10 \mathrm{~Hz}$. The circulation characteristic value $(R)$ (defined as the ratio of the maximum stress to the minimum stress) was 0.1 , and five stress levels were selected: $0.3,0.4,0.5,0.6$, and 0.7 . It is noteworthy that the failure criteria adopted for fatigue testing correspond to the fracture of the specimens.

\section{Results and Discussion}

3.1. Bending Beam Test. Flexural strength is the basic parameter used to establish the bending fatigue equation. The bending beam test was repeated six times; subsequently, Grubbs' method was used to examine and obtain the average of the test results $[42,43]$. Hoe beam replicates were used per material per test condition. The results of the bending beam test of asphalt pavements with different paving technologies, mixture types, and pavement structural thicknesses are given in Table 4 , where $P_{d}$ and $P_{t}$ represent the flexural strength of the beam specimen produced by the double-layer and traditional paving technologies, respectively. In addition, $P_{d} / P_{t}$ represents the ratio of the flexural strength of the beam specimen produced by the two paving technologies.

As presented in Table 4, the bending resistance of the double-layer paved specimens with the same mixture types and pavement structure thicknesses increased by at least $10 \%$ compared with that of the traditionally paved specimens.

The interlayer contact of the traditionally paved specimens exhibits the "cold and hot combination." In this case, the interlayer bonding effect is provided primarily by the tacky coat oil; thus, achieving good extrusion effect of the aggregate between asphalt layers is difficult. In contrast, the interlayer contact of the double-layer paved specimens exhibits the "hot and hot combination." In this case, the extrusion effects between the asphalt layers are significant, merging the surface and bottom layers' asphalt mixtures into one and facilitating the formation of a structural skeleton. These are the primary reasons for the better bending resistance of the double-layer paved specimens.

3.2. Bending Fatigue Test. Figure 5 shows the fatigue test process for double-layer paved beam specimens.

The maximum and minimum load stresses were calculated based on the data presented in Table 4. Subsequently,

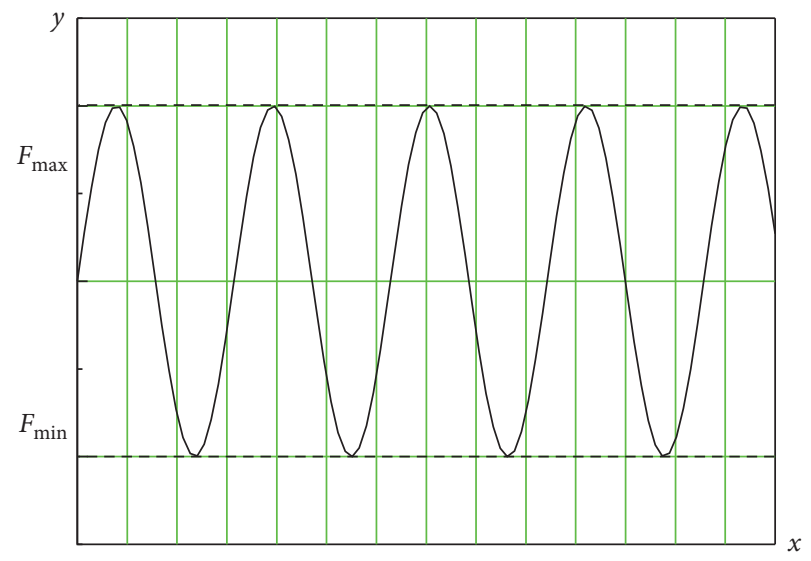

FIGURE 4: Schematic of the loading waveform.

the fatigue life of the specimens was tested. Table 5 gives the results of the bending fatigue test of specimens produced with different paving technologies, mixture types, and pavement structure thicknesses. Note that the hoe beam replicates were used per material per test condition.

Table 5 reveals that the coefficient of variation $\left(C_{V}\right)$ of the fatigue test results is around $10 \%$, which indicates that the test results are stable and reliable. Moreover, Table 5 also shows that the fatigue life of double-layer paved or traditionally paved beam specimens decreases as the stress levels increase. Furthermore, it is noteworthy that the fatigue test results of the specimens are not the same even when the stress levels are the same. In this case, it is difficult to analyze the fatigue data and accurately evaluate which pavement structure combination or paving technology is better.

Recently, some road researchers have successfully applied the Weibull distribution to the fatigue life analysis and observed that such distribution was particularly useful for analyzing the reliability of fatigue life [44, 45]. Therefore, the Weibull distribution was used to analyze the fatigue test data of double-layer beam specimens in this study.

The equivalent fatigue life $(\bar{N})$ and failure probability $(P)$ conform to the following equation $[38,39,46]$ :

$$
P=F(\bar{N})=1-\exp \left(-\frac{\bar{N}^{m}}{u}\right), \quad \bar{N} \geq 1, m, u>0 .
$$

Equation (1) can be transformed into the following equation after using the logarithmic transformation:

$$
\ln \ln \frac{1}{1-P}=m \ln \bar{N}-\ln u=m_{0} \ln N-\ln u,
$$

where $m_{0}$ is the shape parameter, $\bar{N}=N^{1-R}$, and $u$ is the scale parameter.

Substituting the fatigue test results that are presented in Table 5 into the Weibull distribution model (equation (2)), its coefficients such as $m_{0}, \ln u$, and $R^{2}$ are as given in Table 6.

From Table 6, it is observed that the values of $R^{2}$ of the Weibull distribution model are greater than 0.90 . These 
TABLE 4: Results of the bending beam test.

\begin{tabular}{lccccr}
\hline \multicolumn{2}{c}{ Mixture types } & \multicolumn{2}{c}{ Structure thickness $(\mathrm{cm})$} & \multicolumn{2}{c}{ Failure load $(\mathrm{kN})$} \\
Surface layer & Bottom layer & Surface layer & Bottom layer & $P_{d}$ & $P_{t}$ \\
\hline AC-13 & AC-20 & 4 & 6 & 10.43 & 9.23 \\
AC-13 & AC-20 & 3 & 7 & 10.03 & 9.13 \\
AC-16 & AC-20 & 3 & 7 & 9.87 & 8.53 \\
AC-16 & AC-25 & 4 & 6 & 9.10 & 1.13 \\
\hline
\end{tabular}

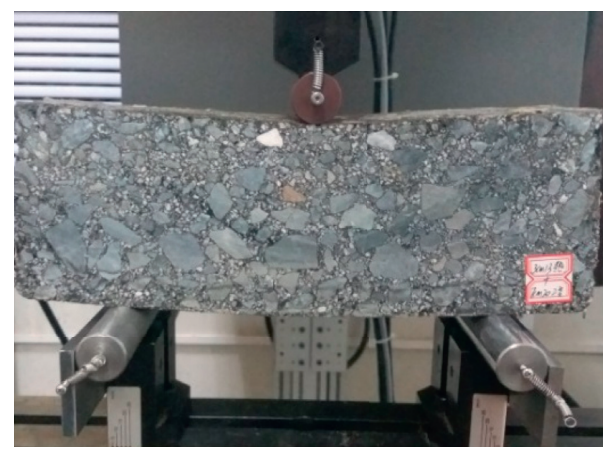

(a)

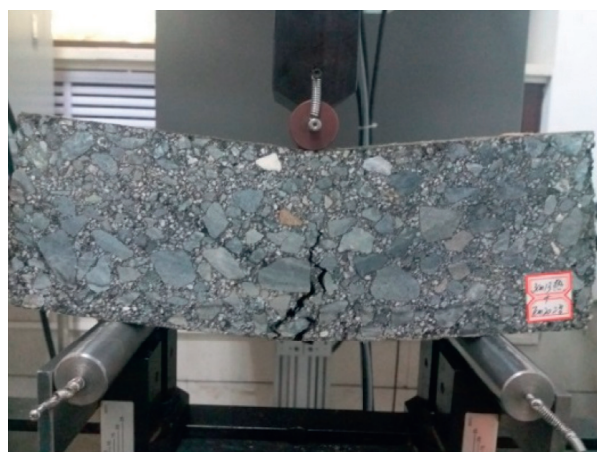

(c)

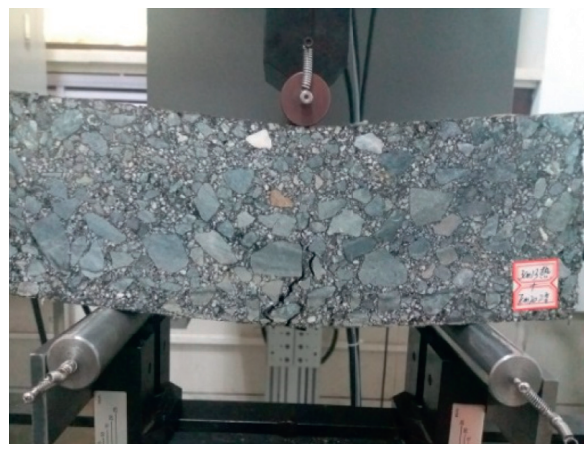

(b)

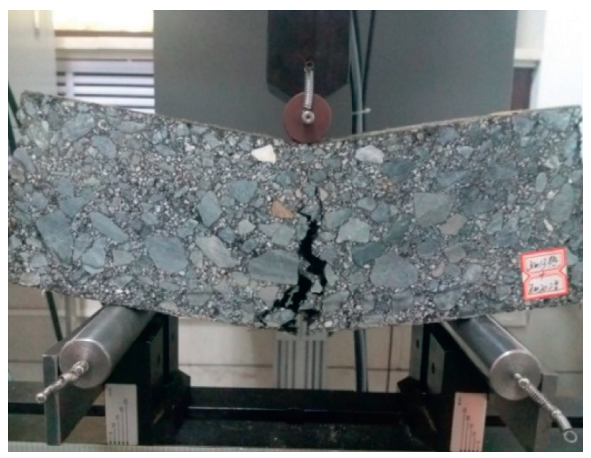

(d)

FIgURE 5: Double-layer beam fatigue test process. (a) Initial specimen. (b) Crack propagation. (c) Further crack propagation. (d) Final specimen.

observations indicate that the fatigue test results examined by the Weibull distribution model are reliable.

3.3. Fatigue Equation. Table 7 shows the equivalent fatigue life $(\bar{N})$ of the double-layer beam specimens under different stress levels $(S)$ and failure probabilities $(P)$ after substituting the coefficients (given in Table 6) into the Weibull distribution model (equation (2)).

The relation between the fatigue life and stress level is shown as follows $[38,39,46]$ :

$$
\lg N=a-b \lg S
$$

where $N$ is the fatigue life of the specimens, $S$ is the stress level used in the fatigue test, and $a$ and $b$ are the coefficients of the fatigue equation.

The value of $a$ represents the intercept on the longitudinal axis of the fatigue equation coordinate axis, reflecting the fatigue performance of the specimens; the larger the value of $a$, the better the fatigue performance of the specimens. The value of $b$ represents the absolute value of the slope of the fatigue equation, reflecting the sensitivity of the fatigue performance of the specimens to the change in the stress level; the smaller the value of $b$, the lower the sensitivity of the fatigue performance of the specimens to the change in the stress level $[39,46]$.

From equation (3) and combinations using the values in Table 7 , the fatigue equations of the double-layer beam specimens were established using regression analysis. Table 8 lists regression coefficients $a, b$, and $R^{2}$ of equation (3).

Table 8 reveals that the correlation coefficients $R^{2}$ of the fatigue equations of the specimens produced with different structure combinations and paving technologies are not less than 0.97 . These results indicate that a good double logarithmic linear relationship exists between the stress level and fatigue life. 
TABLE 5: Bending fatigue test results.

\begin{tabular}{|c|c|c|c|c|c|c|c|c|c|}
\hline \multicolumn{2}{|c|}{ Mixture types } & \multicolumn{2}{|c|}{ Structure thickness $(\mathrm{cm})$} & \multirow[t]{2}{*}{ Paving technologies } & \multicolumn{5}{|c|}{$\begin{array}{l}\text { Fatigue life under the following stress } \\
\text { levels }\end{array}$} \\
\hline Surface layer & Bottom layer & Surface layer & Bottom layer & & 0.3 & 0.4 & 0.5 & 0.6 & 0.7 \\
\hline \multirow{8}{*}{ AC-13 } & \multirow{8}{*}{ AC-20 } & \multirow{8}{*}{ 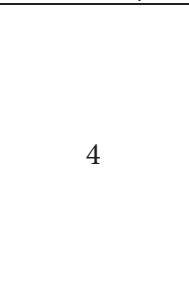 } & \multirow{8}{*}{ 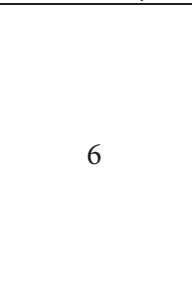 } & \multirow{3}{*}{ Traditional paving } & 4521 & 1550 & 635 & 421 & 258 \\
\hline & & & & & 4690 & 1830 & 696 & 435 & 277 \\
\hline & & & & & 5063 & 1858 & 815 & 482 & 322 \\
\hline & & & & \multirow{4}{*}{ Double-layer paving } & 4.8 & 8.0 & 10.4 & 5.8 & 9.4 \\
\hline & & & & & 5103 & 1530 & 804 & 431 & 223 \\
\hline & & & & & 6146 & 1634 & 830 & 489 & 261 \\
\hline & & & & & 6853 & 1961 & 848 & 591 & 315 \\
\hline & & & & $C_{V}(\%)$ & 11.9 & 10.7 & 2.2 & 13.1 & 14.2 \\
\hline \multirow{8}{*}{ AC-16 } & \multirow{8}{*}{ AC-25 } & \multirow{8}{*}{4} & \multirow{8}{*}{6} & & 4394 & 1371 & 505 & 349 & 157 \\
\hline & & & & Traditional paving & 4517 & 1453 & 568 & 363 & 189 \\
\hline & & & & & 4671 & 1556 & 595 & 405 & 220 \\
\hline & & & & $C_{V}(\%)$ & 2.5 & 5.2 & 6.8 & 6.4 & 13.6 \\
\hline & & & & & 5039 & 1471 & 854 & 526 & 216 \\
\hline & & & & Double-layer paving & 5092 & 1586 & 958 & 593 & 235 \\
\hline & & & & & 5161 & 1665 & 1101 & 641 & 258 \\
\hline & & & & $C_{V}(\%)$ & 1.0 & 5.1 & 10.4 & 8.0 & 7.3 \\
\hline \multirow{8}{*}{ AC-13 } & \multirow{8}{*}{ AC-20 } & \multirow{8}{*}{3} & \multirow{8}{*}{7} & & 5971 & 1648 & 664 & 500 & 270 \\
\hline & & & & Traditional paving & 6039 & 1800 & 778 & 541 & 288 \\
\hline & & & & & 6133 & 1919 & 781 & 566 & 331 \\
\hline & & & & $C_{V}(\%)$ & 1.1 & 6.2 & 7.3 & 5.1 & 8.6 \\
\hline & & & & & 7539 & 2407 & 1023 & 704 & 454 \\
\hline & & & & Double-layer paving & 8337 & 2582 & 1151 & 711 & 468 \\
\hline & & & & & 8981 & 2663 & 1200 & 763 & 545 \\
\hline & & & & $C_{V}(\%)$ & 7.1 & 4.2 & 6.6 & 3.6 & 8.2 \\
\hline \multirow{8}{*}{ AC-16 } & \multirow{8}{*}{ AC-20 } & \multirow{8}{*}{3} & \multirow{8}{*}{7} & \multirow{3}{*}{ Traditional paving } & 4957 & 1628 & 627 & 456 & 245 \\
\hline & & & & & 5188 & 1749 & 680 & 503 & 268 \\
\hline & & & & & 5382 & 1859 & 691 & 529 & 288 \\
\hline & & & & $C_{V}(\%)$ & 3.4 & 5.4 & 4.2 & 6.1 & 6.6 \\
\hline & & & & & 5883 & 1952 & 928 & 503 & 287 \\
\hline & & & & Double-layer paving & 6451 & 2026 & 991 & 522 & 312 \\
\hline & & & & & 6984 & 2171 & 1144 & 534 & 377 \\
\hline & & & & $C_{V}(\%)$ & 7.0 & 4.4 & 8.9 & 2.5 & 11.7 \\
\hline
\end{tabular}

\subsection{Analysis of Influence Factors of Fatigue Property}

3.4.1. Fatigue Life Analysis. Various studies indicate that the tensile stress level generated by the traffic load appearing on an asphalt pavement is generally less than 0.45 [47]. Therefore, in this study, the fatigue life of the specimens was analyzed under the stress level of 0.45 . However, the ratio of the applied load to the material failure strength is defined as the stress level. Therefore, a comparison between fatigue lives under the same stress level cannot accurately reveal the fatigue properties of different materials.

Table 4 reveals that when the stress level is 0.45 , the load $(F)$ of the traditionally paved combination of 4-cm AC-13 surface layer $/ 6-\mathrm{cm}$ AC-20 bottom layer is $4.15 \mathrm{kN}$ $(F=0.45 \times 9.23 \mathrm{kN}=4.15 \mathrm{kN})$. Therefore, the evaluation of the fatigue life of specimens with different paving technologies, mixture types, and pavement structure thicknesses under the same load of $4.15 \mathrm{kN}$ is more reasonable. Table 9 gives the results of the fatigue life of specimens based on the same load.

3.4.2. Effects of Paving Technology. The ratio $\left(N_{d} / N_{t}\right)$ of the fatigue life of the specimens with the same mixture types and structure thicknesses produced by the double-layer and traditional paving technologies is plotted in Figure 6.

Figure 6 indicates that under the load of $F=4.15 \mathrm{kN}$, the fatigue life of the specimens produced by the double-layer paving technology is increased by at least $54 \%$ compared with that produced by the traditional paving technology. This is because for the double-layer paving technology, the surface and bottom layers' asphalt mixture is the "hot and hot combination" during compaction. In this case, the aggregate between the surface and bottom layers' asphalt mixture can form an interlocking joint to avoid discontinuity between the asphalt layers. Thus, the integrity of this 
TABLE 6: Fatigue test results after examination by the Weibull distribution model.

\begin{tabular}{|c|c|c|c|c|c|c|c|}
\hline \multirow{2}{*}{ Pavement structure } & \multirow{2}{*}{ Paving technologies } & \multirow{2}{*}{ Coefficients } & \multicolumn{5}{|c|}{ Stress levels $S$ corresponding to Weibull model coefficients } \\
\hline & & & 0.7 & 0.6 & 0.5 & 0.4 & 0.3 \\
\hline \multirow{6}{*}{ 4-cm AC-13/6-cm AC-20 } & \multirow{3}{*}{ Traditional paving } & $M_{0}$ & 6.7084 & 10.455 & 6.0927 & 7.2798 & 13.153 \\
\hline & & $\ln u$ & 38.334 & 64.190 & 40.442 & 54.749 & 111.79 \\
\hline & & $R^{2}$ & 0.9276 & 0.8772 & 0.9524 & 0.8626 & 0.9296 \\
\hline & \multirow{3}{*}{ Double-layer paving } & $m_{0}$ & 4.5249 & 4.8765 & 29.370 & 5.7919 & 5.2682 \\
\hline & & $\ln u$ & 25.654 & 30.728 & 197.73 & 43.507 & 46.251 \\
\hline & & $R^{2}$ & 0.9858 & 0.9668 & 0.9978 & 0.8923 & 0.9934 \\
\hline \multirow{6}{*}{ 4-cm AC-16/6-cm AC-25 } & \multirow{3}{*}{ Traditional paving } & $m_{0}$ & 4.6639 & 9.6552 & 9.1773 & 12.355 & 25.545 \\
\hline & & $\ln u$ & 24.823 & 57.566 & 58.414 & 90.435 & 215.46 \\
\hline & & $R^{2}$ & 0.9999 & 0.8925 & 0.9690 & 0.9867 & 0.9847 \\
\hline & \multirow{3}{*}{ Double-layer paving } & $m_{0}$ & 8.8248 & 7.9006 & 6.1481 & 12.607 & 65.069 \\
\hline & & $\ln u$ & 48.635 & 50.765 & 42.684 & 93.217 & 555.58 \\
\hline & & $R^{2}$ & 0.9905 & 0.9971 & 0.9849 & 0.9969 & 0.9804 \\
\hline \multirow{6}{*}{$3-\mathrm{cm} \mathrm{AC}-13 / 7-\mathrm{cm} \mathrm{AC}-20$} & \multirow{3}{*}{ Traditional paving } & $m_{0}$ & 7.2826 & 12.512 & 7.7191 & 10.307 & 57.928 \\
\hline & & $\ln u$ & 41.851 & 79.032 & 51.415 & 77.603 & 504.83 \\
\hline & & $R^{2}$ & 0.9254 & 0.9924 & 0.8228 & 0.9995 & 0.9756 \\
\hline & \multirow{3}{*}{ Double-layer paving } & $m_{0}$ & 7.2971 & 15.937 & 9.3307 & 15.04 & 8.9709 \\
\hline & & $\ln u$ & 45.591 & 105.4 & 65.958 & 118.39 & 81.343 \\
\hline & & $R^{2}$ & 0.8216 & 0.7877 & 0.9602 & 0.9769 & 0.9997 \\
\hline \multirow{6}{*}{$3-\mathrm{cm} \mathrm{AC-16/7-cm} \mathrm{AC-20}$} & \multirow{3}{*}{ Traditional paving } & $m_{0}$ & 9.7279 & 10.367 & 14.447 & 11.864 & 19.124 \\
\hline & & $\ln u$ & 54.760 & 64.756 & 94.339 & 88.969 & 163.96 \\
\hline & & $R^{2}$ & 1.000 & 0.9868 & 0.9123 & 0.9995 & 0.9999 \\
\hline & \multirow{3}{*}{ Double-layer paving } & $m_{0}$ & 5.4063 & 26.043 & 7.0776 & 14.187 & 9.1763 \\
\hline & & $\ln u$ & 31.667 & 163.27 & 49.439 & 108.6 & 80.884 \\
\hline & & $R^{2}$ & 0.9191 & 0.9952 & 0.9237 & 0.9436 & 0.9994 \\
\hline
\end{tabular}

TABLE 7: Equivalent fatigue lives of specimens under different failure probabilities.

\begin{tabular}{|c|c|c|c|c|c|c|c|c|}
\hline \multicolumn{2}{|c|}{ Pavement structure } & \multirow[t]{2}{*}{ Paving technologies } & \multirow[t]{2}{*}{ Failure probability (\%) } & \multicolumn{5}{|c|}{$\begin{array}{l}\text { Equivalent fatigue life }(\bar{N}) \text { under the } \\
\text { following stress levels } S\end{array}$} \\
\hline Surface layer & Bottom layer & & & 0.3 & 0.4 & 0.5 & 0.6 & 0.7 \\
\hline \multirow{4}{*}{ 4-cm AC-13 } & \multirow{4}{*}{$6-\mathrm{cm} \mathrm{AC}-20$} & \multirow{2}{*}{ Traditional paving } & 5 & 3918 & 1227 & 469 & 349 & 195 \\
\hline & & & 50 & 4776 & 1755 & 719 & 448 & 287 \\
\hline & & \multirow{2}{*}{ Double-layer paving } & 5 & 3698 & 1095 & 758 & 297 & 150 \\
\hline & & & 50 & 6061 & 1717 & 829 & 506 & 267 \\
\hline \multirow{4}{*}{ 4-cm AC-16 } & \multirow{4}{*}{ 6-cm AC-25 } & \multirow{2}{*}{ Traditional paving } & 5 & 4098 & 1187 & 420 & 286 & 108 \\
\hline & & & 50 & 4538 & 1466 & 558 & 374 & 189 \\
\hline & & \multirow{2}{*}{ Double-layer paving } & 5 & 4879 & 1285 & 639 & 424 & 177 \\
\hline & & & 50 & 5078 & 1580 & 976 & 589 & 237 \\
\hline \multirow{4}{*}{$3-\mathrm{cm} \mathrm{AC}-13$} & \multirow{4}{*}{ 7-cm AC-20 } & \multirow{2}{*}{ Traditional paving } & 5 & 5788 & 1395 & 532 & 437 & 208 \\
\hline & & & 50 & 6054 & 1796 & 745 & 538 & 298 \\
\hline & & \multirow{2}{*}{ Double-layer paving } & 5 & 6225 & 2152 & 855 & 618 & 344 \\
\hline & & & 50 & 8321 & 2559 & 1130 & 728 & 492 \\
\hline \multirow{4}{*}{$3-\mathrm{cm} \mathrm{AC}-16$} & \multirow{4}{*}{ 7-cm AC-20 } & \multirow{2}{*}{ Traditional paving } & 5 & 4529 & 1406 & 558 & 388 & 205 \\
\hline & & & 50 & 5189 & 1751 & 668 & 498 & 268 \\
\hline & & \multirow{2}{*}{ Double-layer paving } & 5 & 4870 & 1712 & 710 & 471 & 202 \\
\hline & & & 50 & 6467 & 2057 & 1026 & 521 & 327 \\
\hline
\end{tabular}

pavement structure is better, the stress concentration generated by the wheel load is reduced, and the fatigue property of the asphalt pavement is improved.

3.4.3. Effects of Mixture Types and Structural Thicknesses. Figure 7 shows the ratio $\left(N_{t} / N_{c}\right)$ of the fatigue life of specimens with different pavement structure combinations produced by the traditional paving technology to that of the pavement structure combination of the $4-\mathrm{cm}$ AC-13 surface layer/6-cm AC-20 bottom layer produced by the same paving technology.

Figure 7 shows that compared with that of the traditionally paved typical pavement structure (4-cm AC-13 surface layer/6-cm AC-20 bottom layer), the fatigue life of the traditionally paved pavement structure combination of 3-cm AC-13 surface layer/7-cm AC-20 bottom layer can be increased by at least $8 \%$, whereas the fatigue lives of other 
TABLE 8: Correlation coefficient of fatigue equation under different failure probabilities.

\begin{tabular}{|c|c|c|c|c|c|c|}
\hline \multicolumn{2}{|c|}{ Pavement structure } & \multirow{2}{*}{ Paving technologies } & \multirow{2}{*}{ Failure probability (\%) } & \multicolumn{3}{|c|}{ Correlation coefficient } \\
\hline Surface layer & Bottom layer & & & $a$ & $b$ & $R^{2}$ \\
\hline \multirow{4}{*}{ 4-cm AC-13 } & \multirow{4}{*}{ 6-cm AC-20 } & \multirow{2}{*}{ Traditional paving } & 5 & 1.7195 & 3.4958 & 0.9849 \\
\hline & & & 50 & 1.9060 & 3.3524 & 0.9949 \\
\hline & & \multirow{2}{*}{ Double-layer paving } & 5 & 1.6612 & 3.6470 & 0.9805 \\
\hline & & & 50 & 1.8691 & 3.5787 & 0.9930 \\
\hline \multirow{4}{*}{ 4-cm AC-16 } & \multirow{4}{*}{ 6-cm AC-25 } & \multirow{2}{*}{ Traditional paving } & 5 & 1.4361 & 4.1407 & 0.9891 \\
\hline & & & 50 & 1.7022 & 3.6957 & 0.9933 \\
\hline & & \multirow{2}{*}{ Double-layer paving } & 5 & 1.7133 & 3.6978 & 0.9845 \\
\hline & & & 50 & 1.9305 & 3.3693 & 0.9776 \\
\hline \multirow{4}{*}{$3-\mathrm{cm} \mathrm{AC}-13$} & \multirow{4}{*}{ 7-cm AC-20 } & \multirow{2}{*}{ Traditional paving } & 5 & 1.7114 & 3.7750 & 0.9722 \\
\hline & & & 50 & 1.9095 & 3.4819 & 0.9859 \\
\hline & & \multirow{2}{*}{ Double-layer paving } & 5 & 1.9969 & 3.3791 & 0.9898 \\
\hline & & & 50 & 2.1194 & 3.3394 & 0.9866 \\
\hline \multirow{4}{*}{ 3-cm AC-16 } & \multirow{4}{*}{ 7-cm AC-20 } & \multirow{2}{*}{ Traditional paving } & 5 & 1.7426 & 3.5895 & 0.9906 \\
\hline & & & 50 & 1.8787 & 3.4499 & 0.9875 \\
\hline & & \multirow{2}{*}{ Double-layer paving } & 5 & 1.7875 & 3.6363 & 0.9918 \\
\hline & & & 50 & 1.9504 & 3.5121 & 0.9977 \\
\hline
\end{tabular}

TABLE 9: Fatigue life of specimens with different paving technologies, mixture types, and pavement structural thicknesses.

\begin{tabular}{|c|c|c|c|c|}
\hline \multicolumn{2}{|c|}{ Pavement structures } & \multirow[t]{2}{*}{ Paving technologies } & \multicolumn{2}{|c|}{$\begin{array}{l}P(\%) \text { in the list correspond to } \\
N\end{array}$} \\
\hline Surface layer & Bottom layer & & 5 & 50 \\
\hline \multirow{2}{*}{ 4-cm AC-13 } & \multirow{2}{*}{ 6-cm AC-20 } & Traditional paving & 855 & 1171 \\
\hline & & Double-layer paving & 1320 & 2000 \\
\hline \multirow{2}{*}{$4-\mathrm{cm} \mathrm{AC-16}$} & \multirow{2}{*}{ 6-cm AC-25 } & Traditional paving & 433 & 594 \\
\hline & & Double-layer paving & 943 & 1201 \\
\hline \multirow{2}{*}{$3-\mathrm{cm} \mathrm{AC}-13$} & \multirow{2}{*}{ 7-cm AC-20 } & Traditional paving & 1006 & 1260 \\
\hline & & Double-layer paving & 1955 & 2503 \\
\hline \multirow{2}{*}{$3-\mathrm{cm} \mathrm{AC-16}$} & \multirow{2}{*}{$7-\mathrm{cm} \mathrm{AC-20}$} & Traditional paving & 732 & 905 \\
\hline & & Double-layer paving & 1425 & 1862 \\
\hline
\end{tabular}

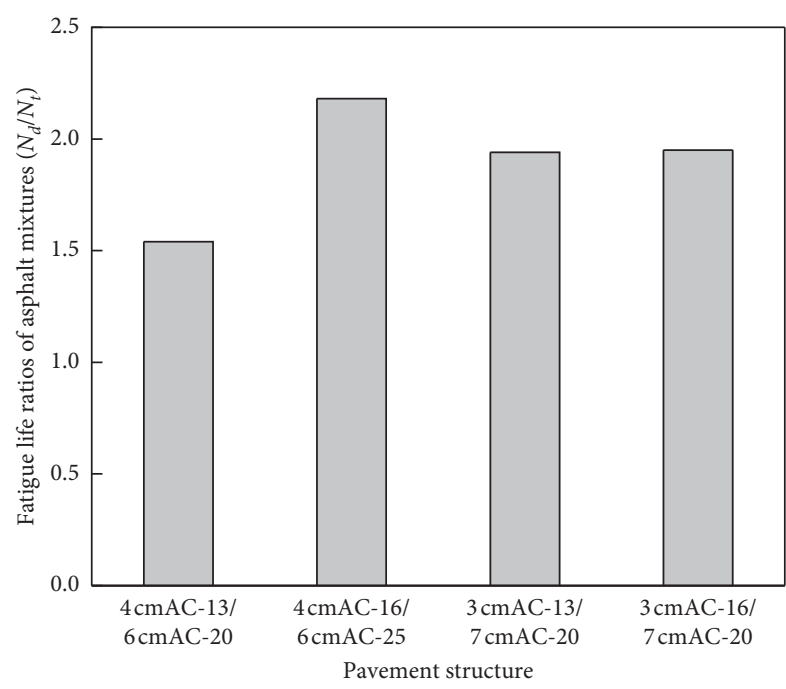

(a)

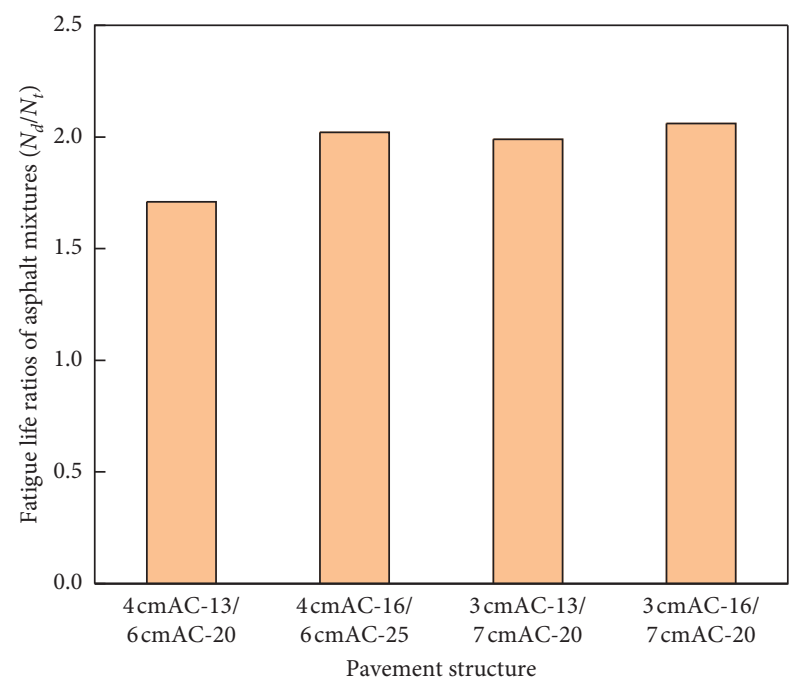

(b)

Figure 6: Fatigue life ratios of the asphalt mixtures with different paving technologies. (a) Failure probability $=5 \%$. (b) Failure probability $=50 \%$. 


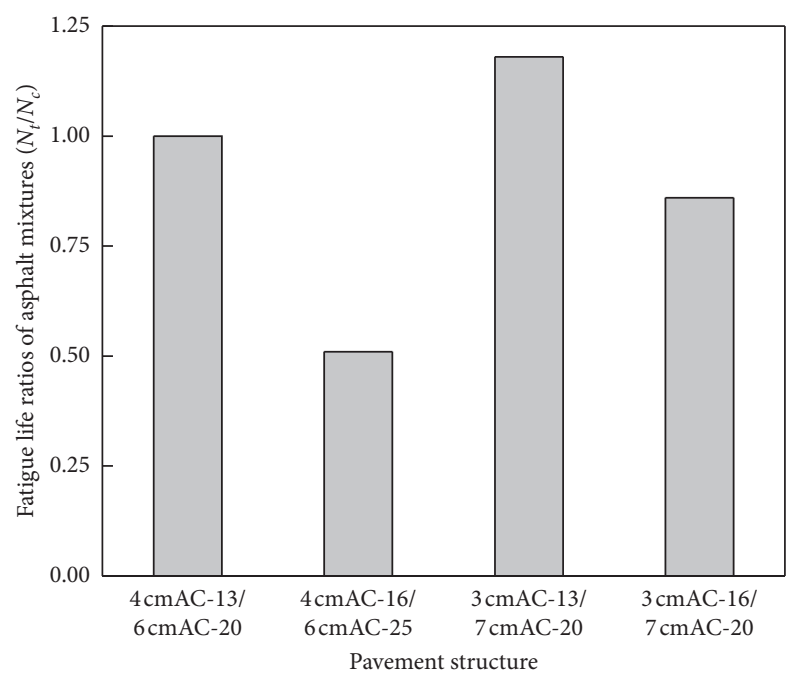

(a)

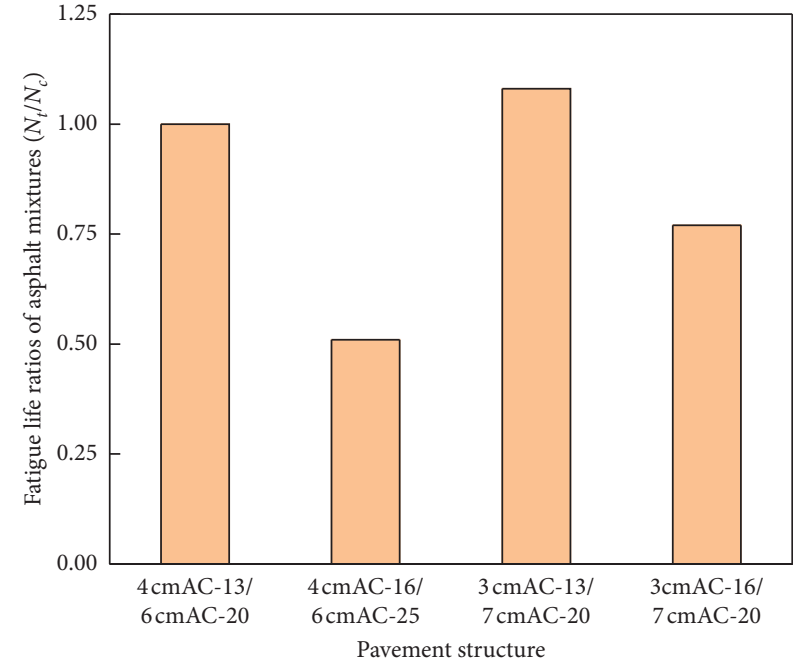

(b)

FIGURE 7: Ratio of the fatigue life of specimens with different pavement structure combinations to the 4-cm AC-13 surface layer/6-cm AC-20 bottom layer pavement structure combination. (a) Failure probability $=5 \%$. (b) Failure probability $=50 \%$.

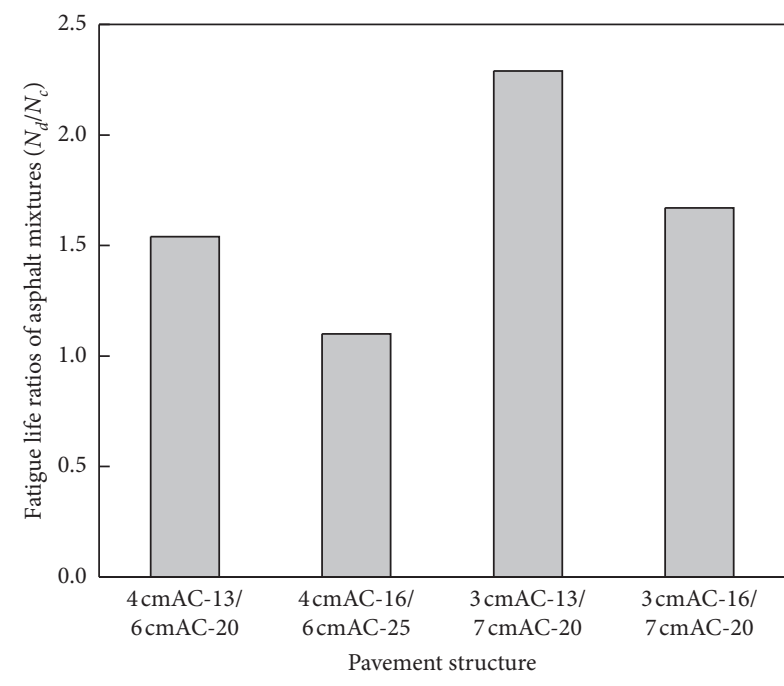

(a)

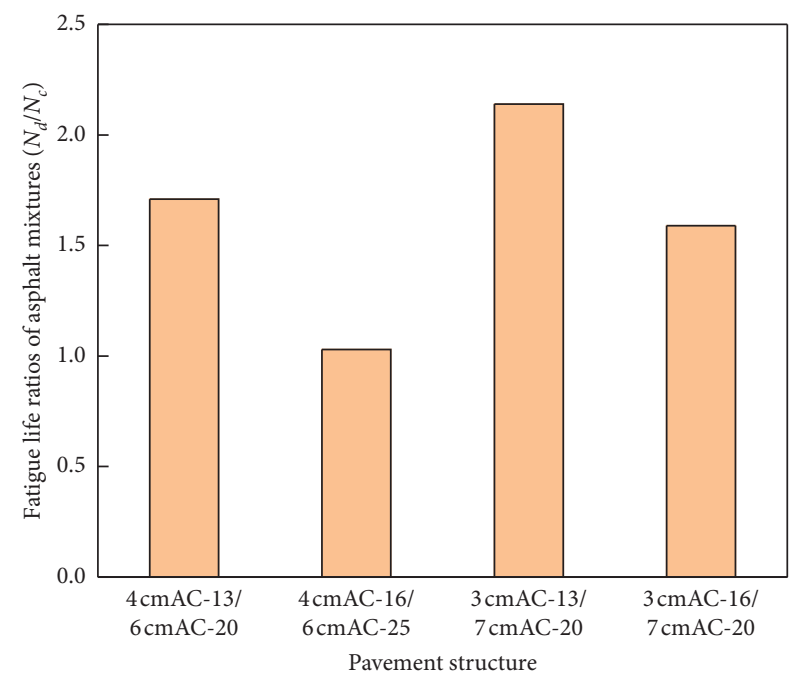

(b)

FIGURE 8: Ratio of fatigue life of specimens with the double-layer paving technology to the 4-cm AC-13 surface layer/6-cm AC-20 bottom layer with traditional paving technology. (a) Failure probability $=5 \%$. (b) Failure probability $=50 \%$.

traditionally paved pavement structures are reduced significantly.

Furthermore, the ratio $\left(N_{d} / N_{c}\right)$ of the fatigue life of specimens with different pavement structure combinations produced by the double-layer paving technology to that of the pavement structure combination of $4-\mathrm{cm}$ AC-13 surface layer/6-cm AC-20 bottom layer produced by the traditional paving technology, is shown in Figure 8.

Figure 8 shows that compared with that of the pavement structure combination of $4-\mathrm{cm}$ AC-13 surface layer/6-cm AC-20 bottom layer produced by the traditional paving technology, the fatigue life of all double-layer pavement structures is improved. The fatigue life of the double-layer pavement structure of the $3-\mathrm{cm}$ AC-13 surface layer $/ 7-\mathrm{cm}$
AC-20 bottom layer combination can be increased by at least $114 \%$.

Figure 8 also shows that under the same structural thickness and with the double-layer paving technology, the fatigue life of the pavement structure combination of AC-13 surface layer/AC-20 bottom layer is higher than those of the AC-16 surface layer/AC-20 bottom layer and AC-16 surface layer/AC-25 bottom layer pavement structure combinations. Under the same test conditions, the fatigue life of the asphalt mixture decreases with an increase in the VV of the asphalt mixture; the larger the $\mathrm{VV}$, the smaller the fatigue life of the asphalt mixture [48-50]. The surface layer of the combination of the AC13 surface layer/AC-20 bottom layer is the AC-13 asphalt 
mixture, whereas the bottom layer is the same as that in the AC-16 surface layer/AC-20 bottom layer combination. Thus, the relatively smaller VV (Table 3 ) of the AC-13 asphalt mixture compared with that of the AC-16 asphalt mixture can effectively hinder the expansion of cracks, thereby improving the fatigue properties of the mixtures $[48,49]$. Moreover, the VVs of the surface layer and bottom layers' asphalt mixtures of the AC-13 surface layer/AC-20 bottom layer combination are smaller than those the pavement structure combination of the AC-16 surface layer/AC-25 bottom layer, thereby relieving the stress concentration of the asphalt pavement and the development of cracks and indicating better fatigue properties [48, 49].

Furthermore, as shown in Figure 8, for the mixture-type combination of AC-13 surface layer/AC-20 bottom layer, the fatigue life of the thickness combination of $3-\mathrm{cm}$ surface layer/ $7-\mathrm{cm}$ bottom layer is longer than that of the thickness combination of the $4-\mathrm{cm}$ surface layer/6- $\mathrm{cm}$ bottom layer. The thickness values of the bottom layer asphalt mixture affect the antifatigue cracking ability of the pavement [51, 52]. When the mixture types are the same, increasing the thickness of the bottom layer can effectively improve the fatigue performance of the double-layer pavement [52]. This is the primary reason why the pavement structure combination of $3-\mathrm{cm}$ surface layer/7$\mathrm{cm}$ bottom layer demonstrates better fatigue resistance than that of the $4-\mathrm{cm}$ surface layer/6-cm bottom layer structure combination.

\section{Conclusions}

In this study, the effects of paving technologies, pavement materials, and structures on the fatigue properties of a double-layer asphalt pavement were investigated. The following conclusions are obtained from the results:

(1) The asphalt mixture specimens produced by the double-layer paving technology with the same mixture types and pavement structure thicknesses exhibit higher flexural strength and fatigue life than those produced by the traditional paving technology.

(2) The bending beam fatigue test shows high practicality, repeatability, and data consistency. The fatigue life of the double-beam mixture specimens obeys the Weibull distribution and the fatigue equations with different paving technologies, mixture-type combinations, and pavement structural thicknesses effectively reflect the fatigue life of the combination specimens.

(3) The fatigue life of the $3-\mathrm{cm}$ surface layer/7-cm bottom layer pavement structure combination is better than that of the pavement structure combination of $4-\mathrm{cm}$ surface layer/6- $\mathrm{cm}$ bottom layer when the mixture-type combinations are identical.

(4) The double-layer pavement with 3-cm AC-13 surface layer and 7-cm AC-20 bottom layer combination is applicable to the field and industry and will be effective in improving the fatigue property of asphalt pavements.
Compared with the traditionally paved typical pavement structure (4-cm AC-13 surface layer/6-cm AC-20 bottom layer), the 3-cm AC-13 surface layer/7-cm AC-20 bottom layer with double-layer paving technology not only saves the asphalt binder (the asphalt content used in AC-13 is higher than that of the AC-20) and tacky coat oil but also improves the durability of asphalt pavements. Thus, the cost of construction and maintenance of asphalt pavements are obviously lower. Finally, the current study was focused primarily on the effects of paving technologies, pavement materials, and structures on the fatigue properties of doublelayer asphalt pavements. Accordingly, our future study will explore their effects on the low-temperature anticracking performance of asphalt pavements.

\section{Data Availability}

The data used to support the findings of this study are included within the article.

\section{Conflicts of Interest}

The authors declare that they have no conflicts of interest.

\section{Acknowledgments}

This research was supported by the Scientific Project from Zhejiang Provincial Communication (Grant No. 2015J23), Scientific Project from Henan Provincial Communication (Grant No. 2020J-2-2), and Scientific Research of Central Colleges of China for Chang'an University (Grant No. 300102218212).

\section{References}

[1] J. B. Sousa, J. C. Pais, M. Prates, R. Barros, P. Langlois, and A.-M. Leclerc, "Effect of aggregate gradation on fatigue life of asphalt concrete mixes," Transportation Research Record: Journal of the Transportation Research Board, vol. 1630, no. 1, pp. 62-68, 1998.

[2] S. Bhattacharjee, J. S. Gould, R. B. Mallick, and F. Hugo, "An evaluation of use of accelerated loading equipment for determination of fatigue performance of asphalt pavement in laboratory," International Journal of Pavement Engineering, vol. 5, no. 2, pp. 61-79, 2004.

[3] D. H. Timm and D. E. Newcomb, "Perpetual pavement design for flexible pavements in the US," International Journal of Pavement Engineering, vol. 7, no. 2, pp. 111-119, 2006.

[4] J. Žák, C. L. Monismith, and D. Jarušková, "Consideration of fatigue resistance tests variability in pavement design methodology," International Journal of Pavement Engineering, vol. 16, no. 1, pp. 91-96, 2015.

[5] F. Tang, T. Ma, Y. Guan, and Z. Zhang, "Parametric modeling and structure verification of asphalt pavement based on BIMABAQUS," Automation in Construction, vol. 111, Article ID 103066, 2020.

[6] F. Tang, T. Ma, J. Zhang, Y. Guan, and L. Chen, "Integrating three-dimensional road design and pavement structure analysis based on BIM," Automation in Construction, vol. 113, Article ID 103152, 2020.

[7] Y. Chen, G. Tebaldi, R. Roque, and G. Lopp, "Effects of trackless tack interface on pavement top-down cracking 
performance," Procedia-Social and Behavioral Sciences, vol. 53, no. 3, pp. 432-439, 2012.

[8] J. Wang, F. Xiao, Z. Chen, X. Li, and S. Amirkhanian, "Application of tack coat in pavement engineering," Construction and Building Materials, vol. 152, pp. 856-871, 2017.

[9] T. Chen, Y. Luan, T. Ma, J. Zhu, X. Huang, and S. Ma, "Mechanical and microstructural characteristics of different interfaces in cold recycled mixture containing cement and asphalt emulsion," Journal of Cleaner Production, vol. 258, Article ID 120674, 2020.

[10] T. Chen, T. Ma, X. Huang, S. Ma, F. Tang, and S. Wu, "Microstructure of synthetic composite interfaces and verification of mixing order in cold-recycled asphalt emulsion mixture," Journal of Cleaner Production, vol. 263, Article ID 121467, 2020.

[11] J. Zhu, T. Ma, J. Fan, Z. Fang, T. Chen, and Y. Zhou, "Experimental study of high modulus asphalt mixture containing reclaimed asphalt pavement," Journal of Cleaner Production, vol. 263, Article ID 121447, 2020.

[12] H. Ziari and M. M. Khabiri, "Interface condition influence on prediction of flexible pavement life," Journal of Civil Engineering and Management, vol. 13, no. 1, pp. 71-76, 2007.

[13] S. Shieldscook and P. C. Taylor, "Working a double life: twolift paving makes a comeback in the US," Roads Bridges, vol. 47 , pp. 32-35, 2009.

[14] J. Hu, D. W. Fowler, M. S. Siddiqui, and D. P. Whitney, "Feasibility study of two-lift concrete paving," Technical report FHWA/TX-14/0-6749-1, US Department of Transportation, Washington, DC, USA, 2014.

[15] Y. L. Wang, Z. Q. Zhang, and B. G. Wang, "Performance of asphalt concrete pavement with double-layer paving technology," Journal of China and Foreign Highway, vol. 27, no. 6, pp. 66-70, 2007, in Chinese.

[16] Y. Q. An, "The technology of double deck paving of asphalt pavement," in Proceedings of the 2nd International Conference on Material Engineering and Application (ICMEA), Wuhan, China, 2015.

[17] China Communications Press, Ministry of Transport of the People's Republic of China, Technical Specifications for Construction of Highway Asphalt Pavements (JTG F40-2004), China Communications Press, Beijing, China, in Chinese.

[18] F. Z. Shi, Study on the double layer continuous paving technology of Asphalt pavement, Ph.D. dissertation, Chang'an University, Xi'an, China, 2006.

[19] S. Großmann, T. Weyrauch, S. Saal, and W. Haase, "Internal electrical field distribution in double layer polymer stacks as studied by electroabsorption," Optical Materials, vol. 9, no. 1-4, pp. 236-239, 1998.

[20] S. Mueller, "Compact asphalt-advantages and disadvantages of a new technology, choice for sustainable development," in Proceedings of the 23rd PIARRC World Road Congress, Paris, France, September 2007.

[21] P. A. Morgan, R. E. Stait, S. Reeves, and M. Clifton, The Feasibility of Using Twin-Layer Porous Asphalt Surfaces on England's Strategic Road Network, Transport Research Laboratory, Wokingham, UK, 2007.

[22] T. P. Füleki, "Improving pavement performance by compactasphalt technology," Pollack Periodica, vol. 4, no. 3, pp. 111-120, 2009.

[23] T. Kuennan, "One and one is one," Better Roads, vol. 80, no. 9, pp. 12-21, 2010.

[24] L. F. Wang, "Study on shear performance of double pavement pavement," Highway Automotive and Applation, vol. 4, pp. 82-85, 2010, in Chinese.
[25] C. Gharabaghy, P. Arnold, K. Scharnigg, and C. Schulze, State-of-the-Art Experience in the Use of the Compact Asphalt Paver for the Construction of Thin-Bed Low Noise Open-Pored 2-course Asphalt Surfacings: State-of-the-Art Technology and Practice in the Netherlands and Germany, Aachen Institute for Highway/RWTH Aachen, Aachen, Germany, 2010.

[26] Y. Li, "Analysis of economy of heat-to-heat paving technique for asphalt pavement," Road Machinery and Construction Mechanization, vol. 28, no. 8, pp. 54-60, 2011, in Chinese.

[27] J. Liu, S. Saboundjian, P. Li, B. Connor, and B. Brunette, "Laboratory evaluation of sasobit-modified warm-mix asphalt for alaskan conditions," Journal of Materials in Civil Engineering, vol. 23, no. 11, pp. 1498-1505, 2011.

[28] C. H. Wang, K. Mu, J. J. Zhao, and X. C. Wang, "Heat losing and effective compacting time of double layer spreading pavement," Journal of Chang'an University (Natural Science Edition), vol. 33, no. 5, pp. 7-12, 2013, in Chinese.

[29] Y. H. Yang, Y. P. Ren, and X. C. Wang, "Fatigue performance of asphalt surface layers in double-layer paving system," Journal of Building and Materials, vol. 18, no. 3, pp. 458-463, 2015, in Chinese.

[30] Y. J. Jiang, H. W. Lin, J. S. Xue, Z. C. Han, and Z. J. Chen, "Influences of pavement material and structure on the hightemperature stability of double-layer pavements," Journal of Materials in Civil Engineering, vol. 32, no. 3, Article ID 4020020, 2020.

[31] L. F. Walubita, Comparison of fatigue analysis approaches for predicting fatigue lives of hot-mix asphalt concrete (HMAC) mixtures, Ph.D. dissertation, Texas A\&M University, College Station, TX, USA, 2006.

[32] L. F. Walubita, G. S. Simate, E. Ofori-Abebresse, A. E. Martin, R. L. Lytton, and L. E. Sanabria, "Mathematical formulation of HMA crack initiation and crack propagation models based on continuum fracture-mechanics and work-potential theory," International Journal of Fatigue, vol. 40, pp. 112-119, 2012.

[33] L. F. Walubita, "The overlay tester: a sensitivity study to improve repeatability and minimize variability in the test results," Technical Research Report\# FHWA/TX-12/0-66071, Texas Transportation Institute, College Station, TX, USA, 2012.

[34] L. F. Walubita, A. N. Faruk, and Y. Koohi, "The overlay tester (OT): comparison with other crack test methods and recommendations for surrogate crack tests," Technical Research Report\# FHWA/TX-12/0-6607-2, TTI-Texas A\&M University System, College Station, TX, USA, 2013.

[35] L. F. Walubita, A. N. M. Faruk, A. E. Alvarez, and T. Scullion, "The Overlay Tester (OT): using the fracture energy index concept to analyze the OT monotonic loading test data," Construction and Building Materials, vol. 40, pp. 802-811, 2013.

[36] L. F. Walubita, B. P. Jamison, G. Das et al., "Search for a laboratory test to evaluate crack resistance of hot-mix asphalt," Transportation Research Record: Journal of the Transportation Research Board, vol. 2210, no. 1, pp. 73-80, 2011.

[37] L. F. Walubita and A. E. Martin, "Laboratory fatigue characterization of asphalt mixtures using the flexural bending beam fatigue test," in Proceedings of the Athens 2007 International Conference: Advanced Characterization of Pavements and Soil Engineering Materials, Athens, Greece, 2007.

[38] J. Xue and Y. Jiang, "Analysis on the fatigue properties of vertical vibration compacted lime-fly ash-stabilized macadam," Construction and Building Materials, vol. 155, pp. 531-541, 2017. 
[39] Y. Jiang, C. Deng, J. Xue, H. Liu, and Z. Chen, "Investigation of the fatigue properties of asphalt mixture designed using vertical vibration method," Road Materials and Pavement Design, vol. 21, no. 5, pp. 1454-1469, 2020.

[40] A. A. Tayebali, J. A. Deacon, and C. L. Monismith, "Development and evaluation of dynamic flexural beam fatigue test system," Transportation Research Record: Journal of the Transportation Research Board, vol. 1545, no. 1, pp. 89-97, 1996.

[41] X. Shu, B. Huang, and D. Vukosavljevic, "Laboratory evaluation of fatigue characteristics of recycled asphalt mixture," Construction and Building Materials, vol. 22, no. 7, pp. 1323-1330, 2008.

[42] L. F. Fan, L. N. Y. Wong, and G. W. Ma, "Experimental investigation and modeling of viscoelastic behavior of concrete," Construction and Building Materials, vol. 48, no. 48, pp. 814-821, 2013.

[43] L. F. Fan, Z. J. Wu, Z. Wan, and J. W. Gao, "Experimental investigation of thermal effects on dynamic behavior of granite," Applied Thermal Engineering, vol. 125, pp. 94-103, 2017.

[44] B. W. Jo, S. Chakraborty, M. A. Sikandar, and Y. S. Lee, "Prediction of the failure stress of hydrogen-rich water based cement mortar using the Weibull distribution model," KSCE Journal of Civil Engineering, vol. 22, no. 5, pp. 1827-1839, 2018.

[45] G. Murali, R. Gayathri, V. R. Ramkumar, and K. Karthikeyan, "Two statistical scrutinize of impact strength and strength reliability of steel fibre-reinforced Concrete," KSCE Journal of Civil Engineering, vol. 22, no. 1, pp. 257-269, 2017.

[46] Y. Jiang, C. Deng, J. Xue, and Z. Chen, "Investigation into the performance of asphalt mixture designed using different methods," Construction and Building Materials, vol. 177, pp. 378-387, 2018.

[47] J. Sun, "Research on fatigue cracking prediction model of asphalt mixture based on stress control model," M.D. thesis, South China University of Technology, Guangzhou, China, 2010.

[48] S. Abo-Qudais and I. Shatnawi, "Prediction of bituminous mixture fatigue life based on accumulated strain," Construction and Building Materials, vol. 21, no. 6, pp. 1370-1376, 2007.

[49] G. Valdés, F. Pérez-Jiménez, and A. Martínez, "Effect of temperature and asphalt mixture type on the fatigue behaviour of flexible pavements," Revista de la construcción, vol. 11, no. 1, pp. 87-100, 2012.

[50] D. Han, L. Wei, and J. Zhang, "Experimental study on performance of asphalt mixture designed by different method," Procedia Engineering, vol. 137, pp. 407-414, 2016.

[51] B. Radovskiy, "Analytical formulas for film thickness in compacted asphalt mixture," Transportation Research Record, vol. 1829, no. 1, pp. 26-32, 2003.

[52] H. Wen, "Development of a damage-based phenomenological fatigue model for asphalt pavement," Journal of Materials in Civil Engineering, vol. 25, no. 8, pp. 1006-1012, 2012. 